\title{
Can growing old in Brazil involve good health and quality of life?
}

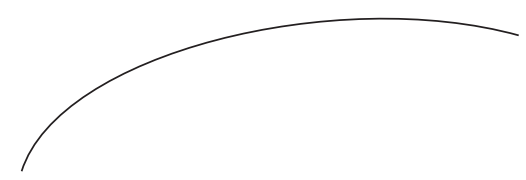

The global phenomenon of longevity is one of the great achievements of the last century. Yet combined with a reduction in fertility, it has caused a drastic aging in the population of the planet. This process began at different times in different countries, and has evolved to varying degrees. In Brazil, its effects are even greater due to the short space of time in which it has occurred.

The speed of the process raises a number of crucial issues not only for researchers in the area of human aging, but for society as a whole. As if the problems inherent to the demographic phenomenon itself were not enough, in Brazil these changes are taking place in a context of social inequality, poverty and fragile institutions. Furthermore, despite a scarcity of resources, a large portion of young people also require quality public programs. In other words, there are two age groups excluded from the production cycle, each with special needs, requiring skill and creativity from the managers of resources in order to overcome the shortage.

We are a young country whose hair is already turning grey. Every year, 700,000 new elderly persons are incorporated into the population - most with chronic diseases and many with functional limitations. In less than 40 years, we have moved from the mortality profile of a young population to one of the complex and costly diseases typical of old age, characterized by multiple chronic illnesses that last for years, requiring constant care, continuous medication and periodic examinations. These changes bring about a significant increase in costs. We must build new paradigms and methods of planning, management and care.

It is for this reason that the area of aging has become a priority in the training of qualified personnel and the development of research projects and models. Proper care for the multiple demands of the elderly is a social issue of interest to us all, and a problem that forms part of the contemporary issues of the century.

All we professionals in the area of Human Aging are aware of the importance of the above issues, yet we do little to bring about the necessary changes. In this context, we are excited about the role of the Agência Nacional de Saúde Suplementar (the National Supplementary Health Agency) (ANS), which in recent years has sought to change the model of the delivery of health services and the form of remuneration in the sector to alternatives that make the user the center of health strategies.

Starting from the identified need to improve care for elderly persons who have health insurance, a book has been published featuring the participation of experts and scholars of the subject, resulting in a set of reflections, experiences and proposals. The aim of this publication 
is to improve the debate and guide us towards providing the best care for this population, linked to the sustainability of the health sector.

The most important thing to remember is that these changes are possible. The health care of the elderly can be reoriented and an organization within the industry created to allow better care and improve financial results. And what will it take to achieve this? Simply that all actors in this area see themselves as responsible for the necessary changes and allow themselves to innovate. Innovate in the care they provide, in order to remunerate and evaluate the quality of the sector, always remembering that often innovate means to rescue and simpler forms of care and values, which have become lost to our health care system. We need to start constructing this new way of caring for the elderly. We cannot wait.

RBGG recommends this book, which can be downloaded free of charge by following the instructions below, using the QR Code.

Enjoy the book!

Renato Veras

Director, UnATI/UERJ and RBGG Editor

\section{SUPPLEMENTARY HEALTH AND THE ELDERLY: AN URGENT NEED FOR THE HEALTH OF SOCIETY AND THE SUSTAINABILITY OF THE SECTOR}

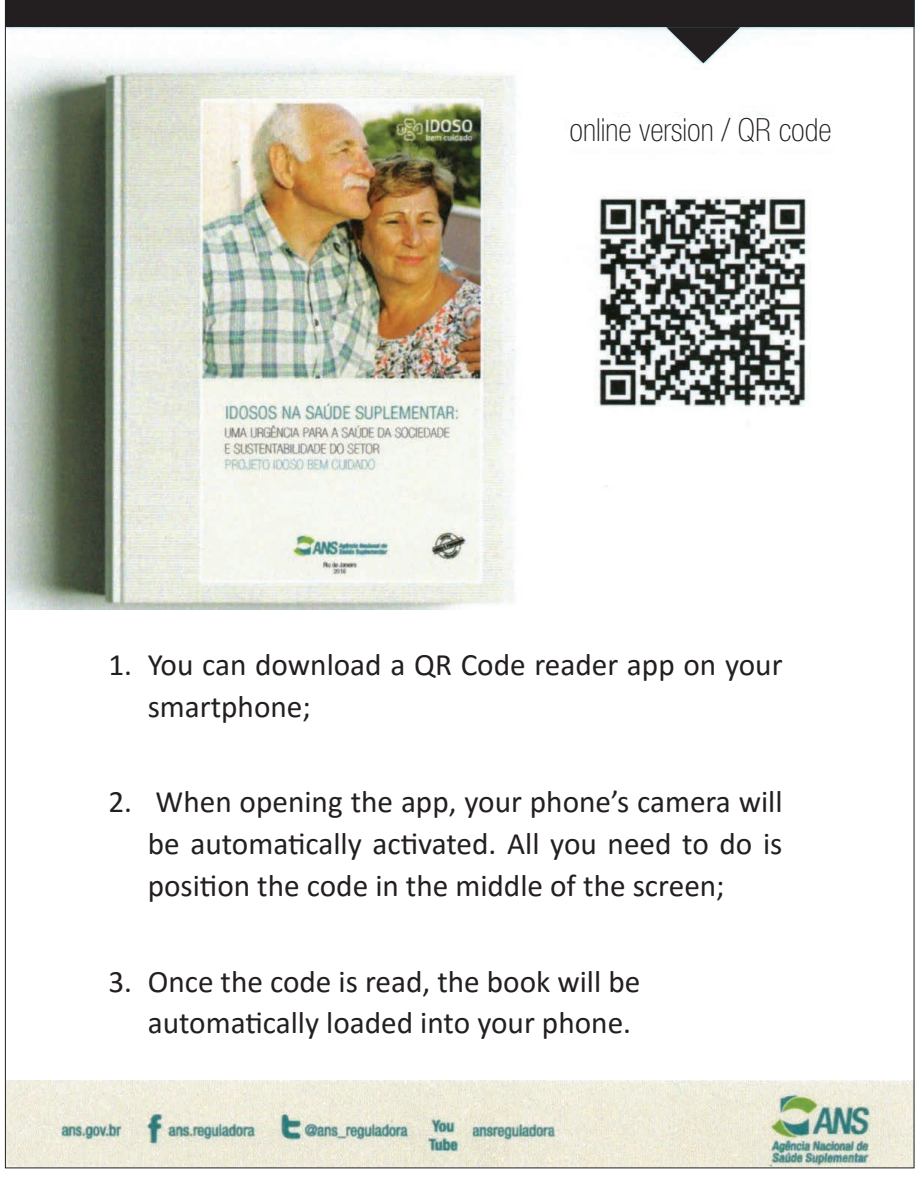

